\title{
ANÁLISE ESPACIAL DE VISIBILIDADE (VIEWSHED) APLICADA A PRESERVAÇÃo DE PAISAGENS CULTURAIS
}

\author{
Edenir Bagio Perin* \\ Francisco Henrique de Oliveira**
}

Resumo: O presente trabalho está relacionado ao desenvolvimento e a identificação dos níveis de sensibilidade visual da Paisagem Cultural remanescente dos Caminhos de Tropas no Planalto de Lages, utilizando como subsídio a Cartografia e o Sistema de Informações Geográficas - SIG. Um importante processo econômico caracterizado pelo transporte de animais, principalmente muares e bovinos da região sul do Brasil e da República do Uruguai para os mercados do Sudeste, caracterizando-se com um dos principais processos de integração do território nacional ao longo dos séculos XVIII e XIX. O método utilizado está estruturado na representação digital e geométrica da área de pesquisa, através de modelos digitais e imagens orbitais. O estudo forneceu as informações sobre a localização das estruturas arqueológicas e permitiu gerar as análises espaciais de visibilidade (viewshed) cujos resultados possibilitaram identificar os níveis de sensibilidade visual da paisagem regional.

Palavras-chave: paisagem cultural; cartografia, sistema de informações geográficas, imagens orbitais; análise espacial de visibilidade.

\section{SPATIAL ANALYSIS OF VISIBILITY (VIEWSHED) APPLIED TO THE PRESERVATION OF CULTURAL LANDSCAPES}

\begin{abstract}
The present work is related to the development of different levels of visual frailty in the Cultural Landscape of troop's routes that are remanescent in the Plateau of Lages Using cartography and GIS as background of knowledge. An important economic process characterized by the transport of animals, mainly donkeys and cattle from the southern Brazil and the Republic of Uruguay to markets in the Southeast, becoming the major integration process throughout the national territory in the eighteenth and nineteenth centuries. The method is structured in the digital and geometric representation of the study area, using digital models and satellite images. The study of the models and images provided information about the locations of archaeological structures as well as establish viewshed's spatial analysis the levels of visual frailty in the regional.
\end{abstract}

Key Words: cultural landscape; cartography, geographic information system, satellite images, spatial analysis of visibility

\section{Introdução}

Este artigo aborda parte da pesquisa realizada entre o IPHAN - Instituto do Patrimônio Histórico Artístico Nacional e a UDESC - Universidade do Estado de Santa Catarina, através do GeoLab - Laboratório de Geoprocessamento. O objetivo principal do projeto é a execução de pesquisas voltadas ao mapeamento dos remanescentes arqueológicos da região do Planalto de Lages, mais especificamente os elementos materiais associados ao Ciclo das Tropas. A área de estudo está situada entre os municípios de Lages e Capão Alto, como mostra o mapa 1.

\footnotetext{
* Geógrafo formado pela Universidade do Sul de Santa Catarina (UNISUL). E-mail: edenirbp@hotmail.com

**E-mail: chico.udesc@gmail.com
} 


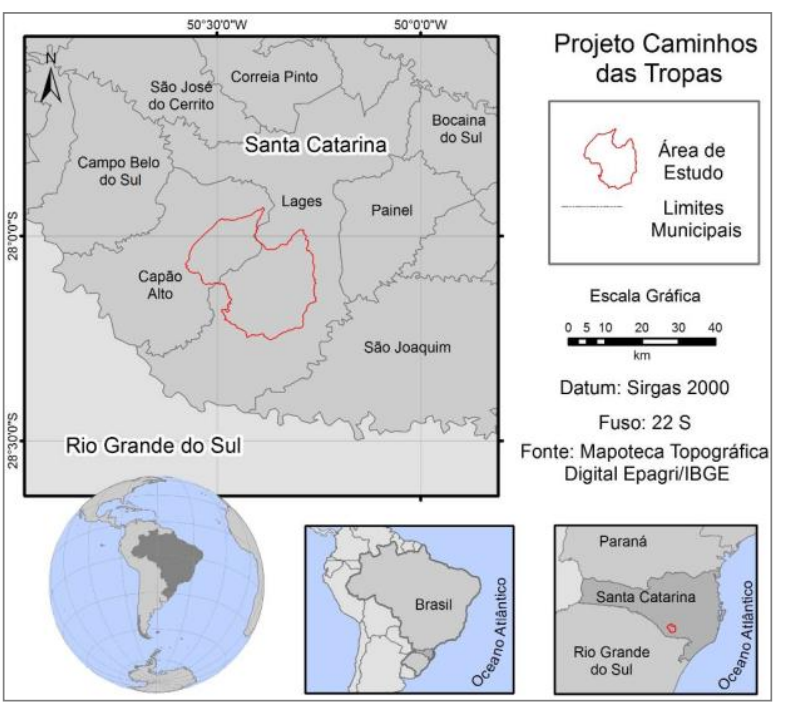

Mapa 1 - Localização da área de pesquisa

Entre os elementos remanescentes do Ciclo das Tropas se destacam construções em taipa de junta seca que formam o traçado dos corredores, por onde os animais eram conduzidos em direção ao Sudeste do país, e também entre as sedes das fazendas da região. Estas fazendas davam suporte aos tropeiros e também constituíam importantes unidades produtivas regionais ligadas a pecuária extensiva. A figura 1 ilustra os corredores existentes ao sul de Lages.

\section{Figura 1 - Aspecto da paisagem dos Caminhos de Tropas ao Sul de Lages/SC. Foto de Ricardo Almeida: Acervo do IPHAN/SC}

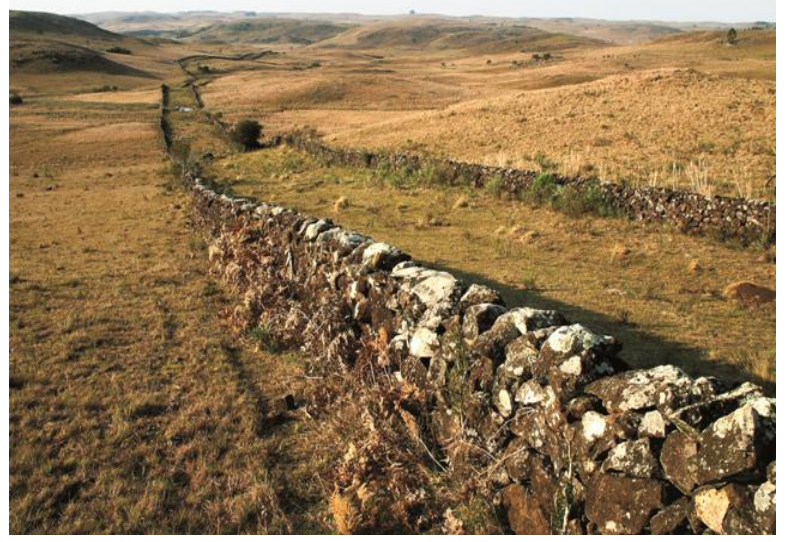

Além das estruturas arquitetônicas e dos corredores que delineiam o caminho propriamente dito, a paisagem regional também merece atenção, uma vez que a combinação dos elementos geomorfológicos locais formam as coxilhas, colinas de litologia predominantemente basálticas. A discreta perda de tropicalidade, principalmente em relação às médias anuais de temperatura do planalto sul brasileiro constitui a "condicionante climática que tornou possível a ampla e contínua instalação de um domínio de natureza extratropical, constituído por araucárias emergentes acima do dossel de matinhas subtropicais" (AB`SABER. 2003, p. 101). Em certas parcelas aparecem mosaicos de campos mesclados a áreas com pinhais, um cenário característico e peculiar que confere significativa originalidade ecológica e paisagística para a região. Este quadro natural que há séculos vem sendo "trabalhado" com o manejo e o controle dos campos aparece associado a um conjunto de elementos arquitetônicos e arqueológicos específicos, o que confere significativo apelo estético a paisagem regional.

Esta combinação de estruturas durou mais que o próprio processo econômico que as criou, assim, elas podem ser entendidas como rugosidades do espaço, pois o processo de formação e evolução do espaço deixou marcas materiais, hoje entendidos como patrimônio cultural, cuja permanência no espaço ultrapassou seu ciclo econômico, permanecendo como uma rugosidade de outra época e outro contexto econômico. Geralmente sua disposição obedece a uma lógica que é ditada externamente pelo modo de produção e internamente pela formaçãosócio-espacial, que por sua vez é resultado da soma entre tecnologia, cultura e organização social (SANTOS, 1980). 
Nos últimos anos, na região esta sendo projetada a instalação de mais de uma dezena de Pequenas Centrais Hidroelétricas PCHs, cujas obras de engenharia e dos elementos de suporte como as linhas de transmissão certamente, se instaladas sem o devido planejamento poderão causar impactos significativos neste quadro paisagístico/patrimonial que optamos por chamar de Paisagem Cultural dos Caminhos de Tropas do Planalto de Lages.

A partir do ano de 2008 a Superintendência do IPHAN em Santa Catarina buscou interiorizar as ações do órgão, que sempre estiveram focadas nos núcleos urbanos tombados das cidades de colonização luso-brasileiras do litoral do Estado, São Francisco do Sul, Laguna e Florianópolis. O foco da gestão passou a ser direcionado principalmente aos bens edificados relacionados à imigraçãoi e aos remanescentes do ciclo do tropeirismo no Planalto de Lages. Até então os bens patrimoniais protegidos pelo IPHAN no Estado sempre foram caracterizados por estruturas cuja dimensão material estava restrita a uma única edificação, um conjunto edificado ou áreas correspondentes a sítios arqueológicos do período pré-colonial. Todas estas estruturas possuem limites facilmente identificáveis, seja pelo traçado urbano ou pelos limites reais das edificações e depósitos arqueológicos.

A necessidade de lidar com elementos patrimoniais situados em área rural e a obrigação de definir uma área de proteção das estruturas relacionadas ao Ciclo do Tropeirismo se caracterizou como um novo desafio de gestão patrimonial frente a Divisão Técnica do IPHAN/SC. A nova problemática colocada tinha origem em duas questões principais: o caráter linear e descontínuo das estruturas e a necessidade de se incorporar a paisagem no instrumento de proteção. A proteção isolada dos bens de relevância arqueológica e patrimonial remanescente do Ciclo das Tropas não parece ter sentido, pois, é justamente o arranjo formado pela combinação dos corredores, passos, fazendas e cemitérios históricos com os campos de altitude, que marcam o que se convencionou chamar de Paisagem Cultural do Tropeirismo. Além da relevância histórica, constitui uma associação de singular apelo estético e ambiental.

$$
\text { Como a paisagem }
$$

impreterivelmente está associada ao que pode ser visto, foi consenso entre os diversos técnicos do IPHAN/SC e os pesquisadores do GeoLab/UDESC (arquitetos, arqueólogos, historiadores, biólogos, procuradores, engenheiros, geógrafos e cientistas sociais) envolvidos no projeto, que a proteção dos bens em questão deveria passar pela documentação do espaço visível a partir de sua posição no espaço.

Diante deste cenário o problema de pesquisa colocado esteve atrelado a sequência lógica para o desenvolvimento de um método ligado ao campo da cartografia e do geoprocessamento, que configure e dê respaldo técnico para a documentação do espaço visível e a identificação dos níveis de sensibilidade da paisagem regional, determinantes para definir as áreas de proteção. Sendo este o objetivo principal da pesquisa.

\section{MAPEAMENTO DAS FEIÇÕES E REPRESENTAÇÃO DIGITAL DO TERRENO}

O mapeamento das feições de interesse (muros de taipa) foi realizado através de imagens orbitais de alta resolução espacial procedentes do sensor Worldview-1, com resolução espacial de 0,5 m NADIR/banda pancromática, acurácia de $5 \mathrm{~m}$ e resolução temporal de 1,7 dias (Figura 2 ). 
O recobrimento da área de estudo foi composto por um mosaico com seis cenas, imageadas entre Abril e Setembro de 2010. As imagens passaram por processo de georreferenciamento e ortorretificação através de um DEM juntamente com o rastreio de 43 pontos de controle em campo.

Figura 2 - Procedimento de vetorização dos muros de taipa através das imagens do sensor Worldview-1.

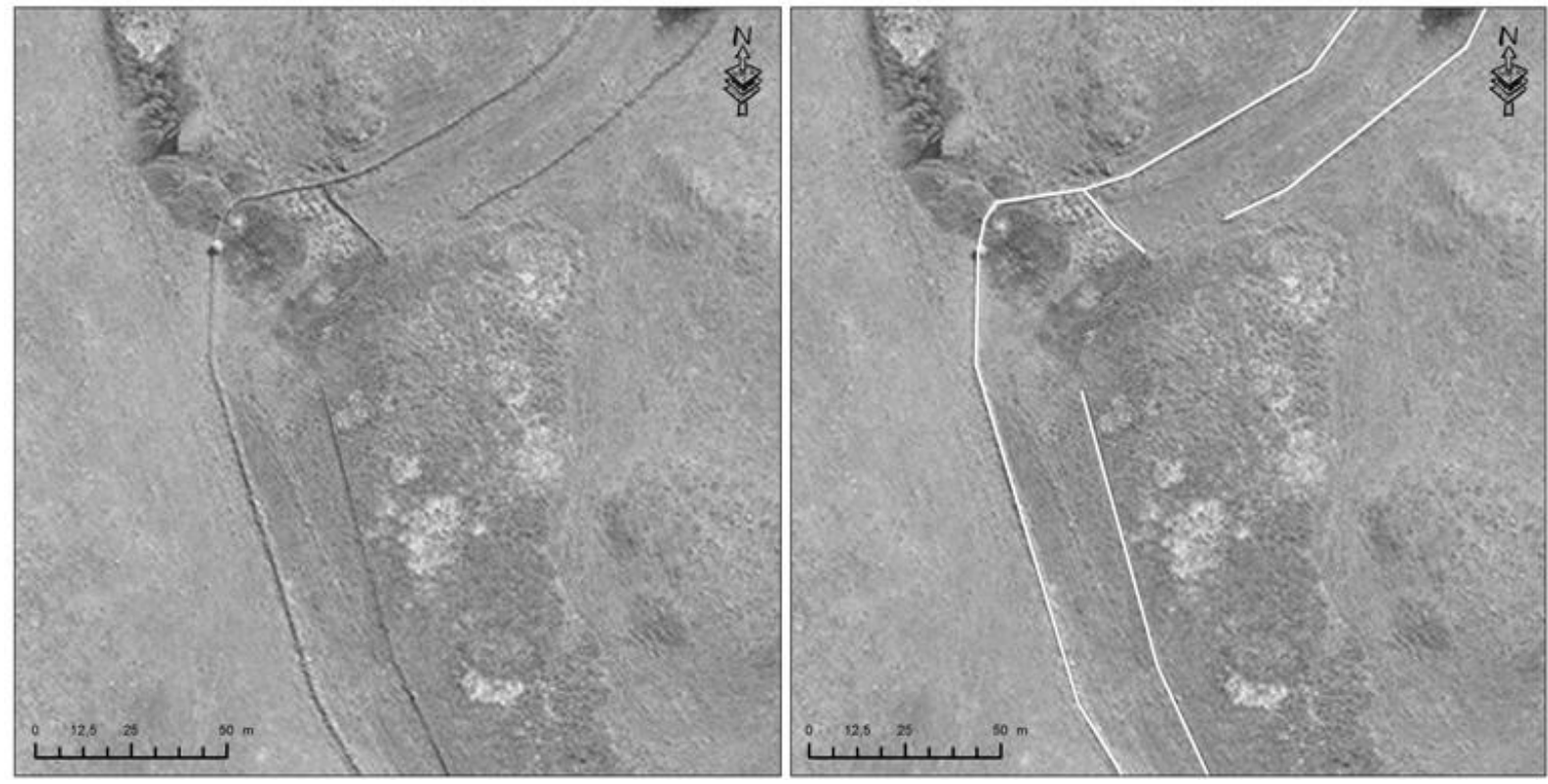

Para gerar o DEM foram utilizadas as bandas do sensor VNIR de uma imagem do sensor Advanced Spacebone Thermal Emission and Reflection Radiometer (ASTER) com possui resolução espacial de $15 \mathrm{~m}$, composto por dois telescópios. Um possui visada vertical que captura resposta do espectro visível nas bandas situadas no verde (Banda 1: $0.52-0.60 \mu \mathrm{m}$ ); vermelho (Banda 2: $0.60-0.69 \mu \mathrm{m}$ ) e também no infravermelho próximo (Banda 3: $0.76-0.86 \mu \mathrm{m}$ ). 0 segundo telescópio possui visada inclinada na direção posterior da mesma órbita, capturando apenas resposta espectral no infravermelho próximo (Banda 4: $0.76-0.86 \mu \mathrm{m}$ ), o que junto da banda NADIR permite gerar estereoscopia.

A utilização da imagem ASTER para gerar modelos de elevação digital não é algo novo, este procedimento encontra-se bastante difundido e testado tanto no meio acadêmico quanto na execução de trabalhos técnicos que envolvem geoprocessamento.

Parma (2007) utilizou a imagem ASTER com resolução espacial de 15 metros para gerar o MDE da cartografia em escala 1:20.000 no âmbito do projeto de reorganização e reestruturação cartográfica do banco de dados das receitas próprias do município do município de Palhoça, Estado de Santa Catarina. Fuckner (2008) aplicou imagens ASTER no estudo do ambiente urbano das cidades de São Paulo e Rio de Janeiro, objetivando estudar o potencial de todas as bandas do sensor, inclusive as termais. Cremon e Filho (2009) através de estereoscopia orbital das bandas $3 \mathrm{~N}$ e $3 \mathrm{~B}$ do sensor ASTER juntamente com a krigagem dos dados SRTM construíram um DEM para a planície alagável do Rio Paraná, objetivando melhorar a identificação das feições geomorfológicas da área de estudo. 
ANÁLISE ESPACIAIS PARA IDENTIFICAÇÃO DOS NÍVEIS DE SENSIBILIDADE VISUAL DA PAISAGEM

\section{Análise de visibilidade - viewshed}

A análise de visibilidade - viewshed identifica as porções de superfície visível de um modelo raster a partir de um ou mais observadores. Por exemplo, a área que um observador consegue avistar se posicionado no topo de uma colina (Figura 3). É muito utilizada para identificar impactos na paisagem que a implantação de obras de infra-estrutura (edifícios, torres, dentre outros) pode causar. Outro uso bastante comum é a determinação das áreas que serão alcançadas pelo sinal de torres de comunicação. De forma sintética, a análise pode documentar cartograficamente o espaço visível por um ou mais observadores.
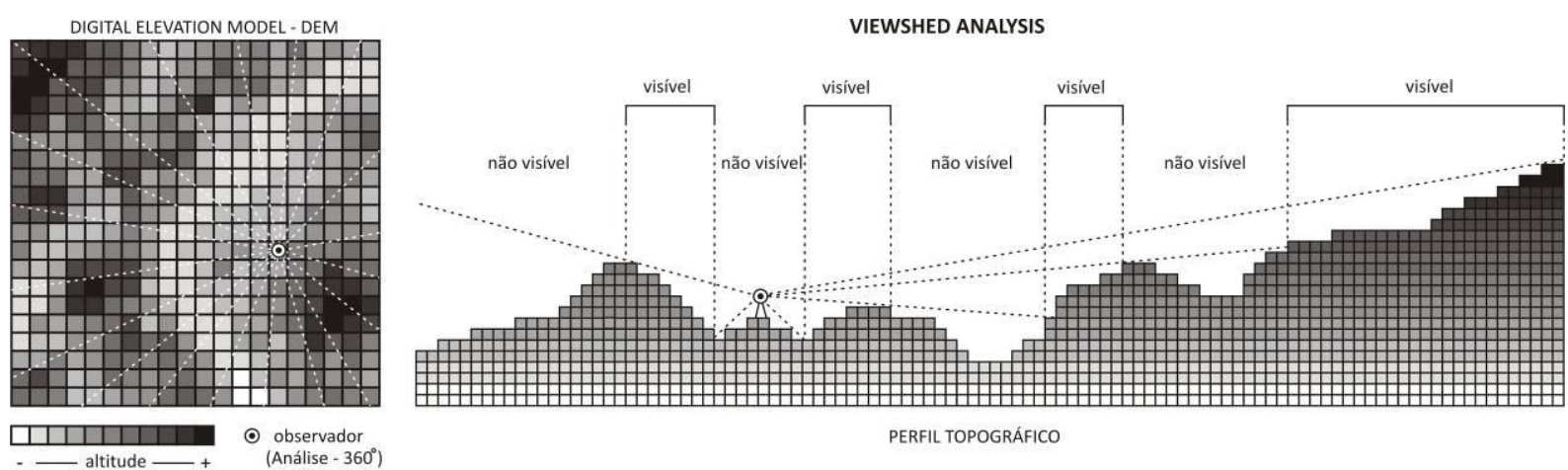

PERFIL TOPOGRÁFICO

Figura 3 - Lógica da análise de visibilidade básica Viewshed

Existem diversas abordagens

entorno do uso da ferramenta aplicada a Arqueologia e Patrimônio Cultural. Merece destaque o trabalho de Moura (2003) direcionado a gestão e planejamento urbano do centro histórico da cidade de Ouro Preto (MG) e a pesquisa de Andreas Kneip (2004) direcionada ao estudo dos sítios arqueológicos na região do complexo lagunar do sul de Santa Catarina.

O trabalho de Moura (2003) em Ouro Preto foi planejado de modo a responder dois questionamentos: 1) De quais pontos da malha urbana uma intervenção poderá ser vista? E 2) Qual será o grau de importância, em termos de visibilidade, do espaço onde a intervenção será realizada? Segundo a autora, as análises de visibilidade abriram ainda outras possibilidades para 0 planejamento urbano. Como "escolha de roteiros turísticos, promoção de mirantes de visitação, incremento de pontos de observação de maior potencial, escolha das localizações mais adequadas para determinados fins, entre outros" (MOURA, 2003, p.186)

O método empregado para obtenção das manchas representativas das áreas visíveis para a cidade de Ouro Preto foi denominada de "Estudo de Eixos Visuais". Em síntese o procedimento partiu da seguinte lógica:

Uma vez identificados 80 pontos ao longo da malha urbana, e desenhados os eixos visuais a partir desses nós de visualização, os eixos foram separados em 20 mapas, com cuidado de não permitir a sobreposição das manchas. As sobreposições não poderiam ocorrer, pois os dados se destinavam a dois fins: estudo de assinaturas de localizações específicas e construção do mapa "Síntese de Eixos Visuais", quando cada mancha deveria ter um valor, e ser sintetizada na busca da classificação dos graus 
de visibilidade ao longo da cidade. Assim, foram evitadas sínteses precoces (MOURA, 2003, p. 189).

Após a obtenção da manchas, os dados foram cruzados no módulo de avaliação SAGA-UFRJ com o objetivo identificar as áreas com maior e menor concentração de eixos visuais. As informações também foram cruzadas com dados altimétricos e áreas de valor cênico. O produto final do trabalho forneceu subsídios para o planejamento e gestão do espaço urbano da cidade de modo a minimizar impactos visuais e orientar os técnicos responsáveis pela gestão do conjunto tombado.

Kneip (2004) em um trabalho voltado ao modelamento e simulação arqueológica para o contexto dos sítios arqueológicos do tipo sambaqui (mounds) identificados na região de Laguna/SC, utilizou análises de visibilidade para distintos cenários cronológicos a partir da localização dos sítios. A análise permitiu inferir que a visibilidade a partir da paleolagoa tinha influência direta na escolha dos locais de implantação dos sítios arqueológicos, dispostos em um padrão circulagunar evolutivo que acompanhava o recuo das margens da lagoa de acordo com a variação do NRMii. A paleolagoa seria, portanto, um dos locais de onde se organizava os aspectos da cultura sambaquieira estudada.

Perin et all (2007) realizaram exercícios de análise espacial com uso da ferramenta viewshed para 29 sítios arqueológicos atribuídos a Tradição Umbu no alto curso da bacia hidrográfica do Rio Tubarão, municípios de Grão Pará e Rio Fortuna, Estado de Santa Catarina. Em síntese, os pesquisadores identificaram significativa intervisibilidade entre os pontos correspondentes a cada sítio arqueológico, situados em um horizonte cronológico que oscila em torno de 1.000 anos BPii. Os resultados obtidos reforçaram a hipótese de uso contemporâneo e compartilhado do espaço regional pelas sociedades précoloniais que habitaram a encosta sul catarinense.

Diferentemente dos casos anteriores, direcionados ao planejamento urbano, a Arqueologia "pura". A utilização das análises viewshed, voltada à identificação dos níveis de sensibilidade visual da paisagem cultural do Planalto de Lages, foi aplicada com o objetivo de fornecer dados para o planejamento e gestão de um espaço situado em área rural.

No software ArcGis 10, utilizado para a realizazação das análises, a ferramenta viewshed pode ser encontrada no ArcToolbox dentro dos campos 3D Analyst Raster Surface - Viewshed ou Spatial Analyst - Surface - Viewshed. Primeiramente é necessário dispor das coordenadas de localização do ponto ao qual deverá ser gerada a análise e 0 modelo raster correspondente ao relevo da região de interesse. Acessando a janela viewshed devese inserir o DEM no campo Input raster e o arquivo shapefile correspondente ao ponto do observador no campo Input Point or polyline observer features ${ }^{i v}$. No campo Output raster deve-se informar o destino do novo arquivo raster gerado com a análise. O campo Zfactor corresponde ao fator de conversão do modelo raster em combinação com os atributos dos observer points, se os dois possuem a mesma unidade de medida, por exemplo, deve-se utilizar o valor " 1 ".

Cada célula de saída do modelo raster que é gerado pela análise recebe um valor que corresponde a quantos pontos de observação podem ser vistos a partir de cada pixel do modelo. Se a análise for gerada a partir de apenas um ponto, os pixels com 
visibilidade terão valor um (1) e aqueles não visíveis do ponto de observação receberão valor zero (0). A análise também funciona para linhas, onde os vértices e os nós funcionam como pontos de observação.

Para uma análise básica a altura do observador é calculada a partir de uma média ponderada por interpolação bilinear dos quatro pixels mais próximos de onde incide o par de coordenadas correspondentes a posição do observador. A análise pode ser controlada a partir da tabela de atributos dos pontos de observação. É possível controlar uma série de variáveis da análise de acordo com a necessidade do usuário. O controle é realizado através das ferramentas SPOT, OFFSETA, OFFSEB, AZIMUTH2, AZIMUTH1, VERT1, VERT2, RADIUS1 e RADIUS2. O quadro 1 , apresenta as funções destas ferramentas.

O modelo raster de saída da análise apresentou valor 0 para as áreas do terreno sem visibilidade (áreas de sombra) e as porções correspondentes ao visível foram estratificadas em 1.877 classes seguindo a seguinte lógica: Para um determinado pixel do modelo com visibilidade para apenas 01 dos 3.006 observadores posicionados nos locais de interesse, a análise irá atribuir valor 01. Um pixel com visibilidade para dois observadores receberá valor de 02 e assim sucessivamente para todo o modelo.

Quadro 1 - Função das ferramentas de controle da análise viewshed no ArcGis10

\begin{tabular}{|c|c|}
\hline FERRAMENTA & FUNÇÃO \\
\hline SPOT & $\begin{array}{l}\text { Referente à altitude do observador. Altura do observador + altitude de sua } \\
\text { posição no DEM (valor obtido por interpolação bilinear das quatro células mais } \\
\text { próximas da coordenada ). }\end{array}$ \\
\hline $\begin{array}{l}\text { OFFSETA } \\
\text { OFFSETB }\end{array}$ & $\begin{array}{l}\text { Corresponde a um valor vertical a ser adicinado no ponto correspondente ao } \\
\text { observador. } \\
\text { Corresponde a um valor vertical a ser adicinado em cada célula do modelo. }\end{array}$ \\
\hline $\begin{array}{l}\text { AZIMUTH1 } \\
\text { AZIMUTH2 }\end{array}$ & $\begin{array}{l}\text { Constituem os dois azimutes que definem os ângulos/limites horizontais da } \\
\text { análise. A varredura sempre prossegue em sentido horário partindo do } \\
\text { AZIMUTH1 para o AZIMUTH2. Os valores de entrada correspondem então a } \\
360^{\circ} \text { estando o } 0 \text { orientado para o Norte. } \\
\text { AZIMUTH } 1 \text { - define o ângulo de início da análise Quando a análise é gerada } \\
\text { sem este item na tabela de atributos, o software adota o valor } 0 \text { como padrão. } \\
\text { AZIMUTH2 - define o ângulo final da varredura e, portanto sempre deve ser } \\
\text { maior que o valor dado para o primeiro. Quando a análise é gerada sem este } \\
\text { item na tabela de atributos o software adota o valor } 360^{\circ} \text { como padrão, } \\
\text { portanto a análise cobrirá } 360^{\circ} \text { a partir do observador. }\end{array}$ \\
\hline VERT1 & $\begin{array}{l}\text { Estes itens definem os ângulos/limites verticais da análise. Os ângulos são } \\
\text { definidos entre } 90^{\circ} \text { e - } 90^{\circ} \text { sendo que a angulação positiva corresponde à } \\
\text { porção acima do plano horizontal e a negativa abaixo. O valor } 0 \text { corresponde a } \\
\text { equivalência da angulação entre valor Z do ponto de observação com o valor do } \\
\text { OFFSETA. Ambos podem ser negativos. } \\
\text { VERT1 - define o limite superior do ângulo horizontal da análise. Quando a } \\
\text { análise é gerada sem este item na tabela de atributos o software adota o valor } \\
90 \text { como padrão. } \\
\text { VERT2 - define o limite inferior do ângulo horizontal da análise. Quando a } \\
\text { análise é gerada sem este item na tabela de atributos o software adota o valor } \\
\text { - } 90 \text { como padrão. }\end{array}$ \\
\hline RADIUS1 & $\begin{array}{l}\text { Determinam o alcance da análise viewshed, delimitando a área de varredura } \\
\text { entre dois raios. Assim as células fora do limite definido serão excluídas da } \\
\text { análise. } \\
\text { RADIUS1 - define a distância do primeiro raio, aquela do onde a análise será } \\
\text { iniciada. No modelo raster de saída gerado a partir da análise as células } \\
\text { situadas entre o observador e a distância até o RADIUS1 não serão vistas, }\end{array}$ \\
\hline
\end{tabular}


porém, poderão bloquear a visibilidade das células entre RADIUS1 e RADIUS2. RADIUS2 - define a distância do segundo raio, aquela que limita a distância da análise e, portanto, seu valor deverá ser maior do que o RADIUS1. Quando a análise é gerada sem este item na tabela de atributos o software adota $\infty$ como padrão para o RADIUS2.

Fonte: ESRI (2011) Viewshed (Spatial Analyst) Using iewshed and Observer Points for visibility analysis

Após a obtenção do modelo de saída da análise viewshed as classes foram reclassificadas em apenas sete intervalos de acordo com o histograma de distribuição dos valores (Mapa 2). A simplificação das classes foi necessária para que o modelo fosse passível de visualização e interpretação, tendo em vista a dificuldade de interpretar o grande número de classes geradas com a análise. O modelo foi reclassificado através da ferramenta reclassify ${ }^{v}$

em uma progressão aritmética (Quadro 2), de acordo com a primeira divisão das 1.877 classes obtidas inicialmente. A memória deste procedimento está representada na tabela 12.

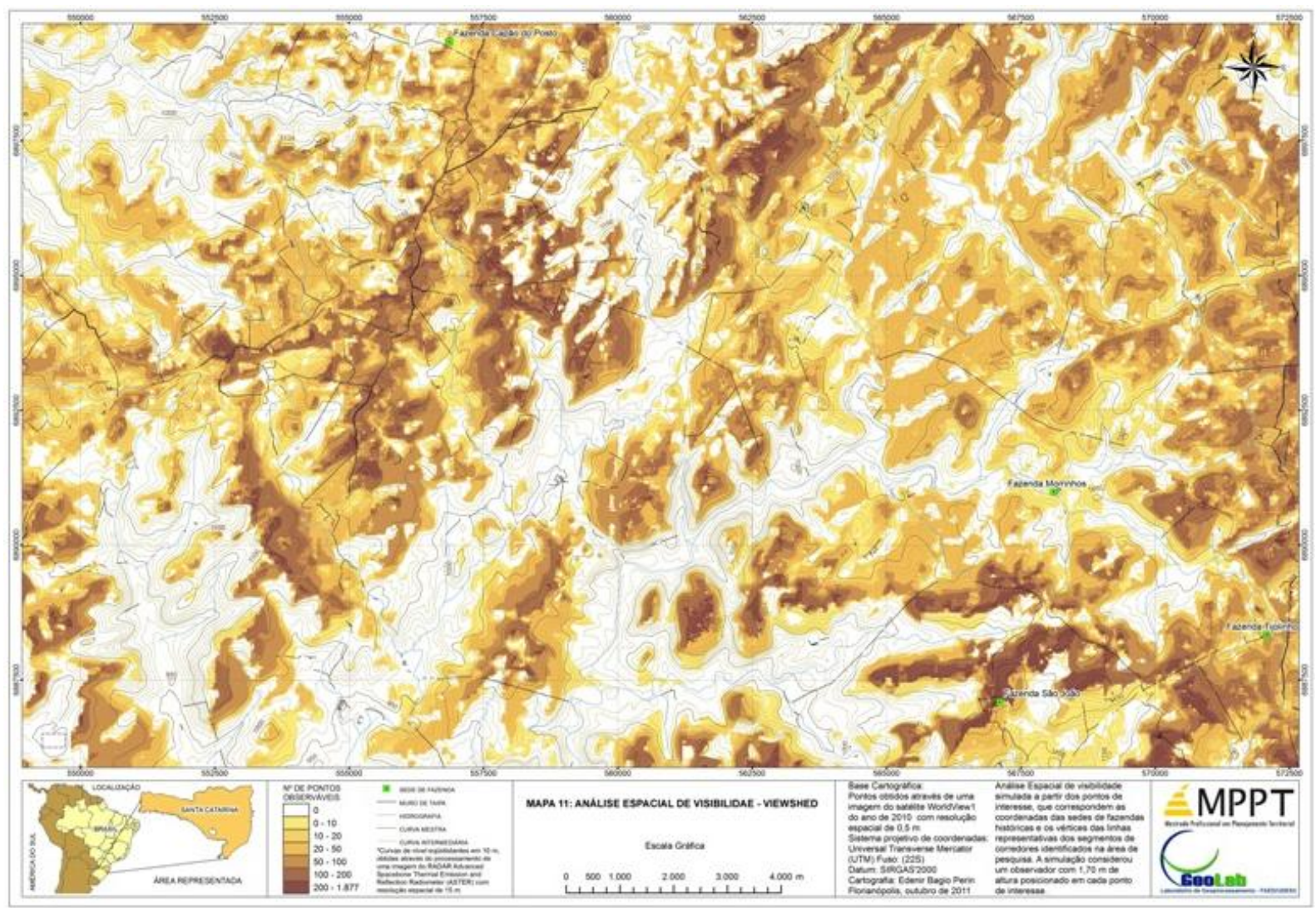

Mapa 2 - Análise espacial de visibilidade - viewshed

Após sua reclassificação, cada classe do modelo foi convertida em polígono através da ferramenta Raster to Polygon. Com a obtenção dos polígonos foi possível calcular a área em $\mathrm{km}^{2}$ de cada classe através da ferramenta Calculate Geometry e Statistics. Os resultados obtidos indicam que $62 \%$ da área visível está concentrada entre o intervalo observação de 20 a 100 pontos observáveis dos 3.006 observadores simulados na análise. 


\section{Quadro 2 - Valores Reclassify Viewshed Analysis}

\begin{tabular}{|c|c|}
\hline $\begin{array}{c}\text { INTERVALOS DE DISTÂNCIA DA ANÁLISE } \\
\text { VIEWSHED }\end{array}$ & $\begin{array}{c}\text { VALOR DA RECLASSIFICAÇÃO DO MODELO } \\
\text { RASTER }\end{array}$ \\
\hline $0-0$ & 0 \\
\hline $0-12,5$ & 1 \\
\hline $12,5-25$ & 2 \\
\hline $25-50$ & 3 \\
\hline $50-100$ & 4 \\
\hline $100-200$ & 5 \\
\hline $200-1877$ & 6 \\
\hline
\end{tabular}

Fonte: Análise gerada através do software ArcGis10

A partir do modelo reclassificado foi construído um primeiro exercício para a identificação dos níveis de sensibilidade visual da paisagem, sendo possível identificar que as áreas de maior visibilidade a partir dos bens correspondem aos interflúvios regionais. Outra constatação esta relacionada a pouca visibilidade dos fundos de vale, influenciada pela geomorfologia regional que é marcada pela presença de vales encaixados e estreitos.

\section{Análise de distância - euclidean distance}

Para identificar os níveis de sensibilidade visual da paisagem a partir dos elementos de interesse também foi necessário levar em consideração o fator distância. Partindo do princípio que a dimensão física da paisagem está indubitavelmente ligada ao que pode ser visto e que a qualidade da visão diminui conforme os objetos se afastam do observador, foi simulada uma análise euclidean distance para traçar zonas buffer a partir de observadores posicionados em cada uma das fazendas e dos pontos correspondentes aos vértices dos muros de taipa dos corredores.

Em síntese, a geração desta análise buscou uma forma de obter um modelo raster com valores contínuos a partir das feições de interesse. O modelo foi gerado com raio total de $10.000 \mathrm{~m}$ e intervalos a cada raio de $1.000 \mathrm{~m}$ (Mapa 3), reclassificados posteriormente com valores invertidos através da ferramenta Reclassify conforme apresentado no quadro 3. Obteve-se um novo modelo raster com valores decrescentes, seguindo a lógica entre qualidade da visão e distância. A inversão dos valores levou em consideração o fato de que a sensibilidade da paisagem será maior nos espaços mais próximos das estruturas de interesse, pois, possíveis alterações serão mais facilmente percebidas.

A definição do limite de $10.000 \mathrm{~km}$ para a geração da análise foi determinada pelo tamanho da área de pesquisa em relação à posição dos bens. Contudo, seu alcance pode ser alterado para mais ou para menos de acordo com a necessidade imposta pelo tamanho da área objeto da análise. 


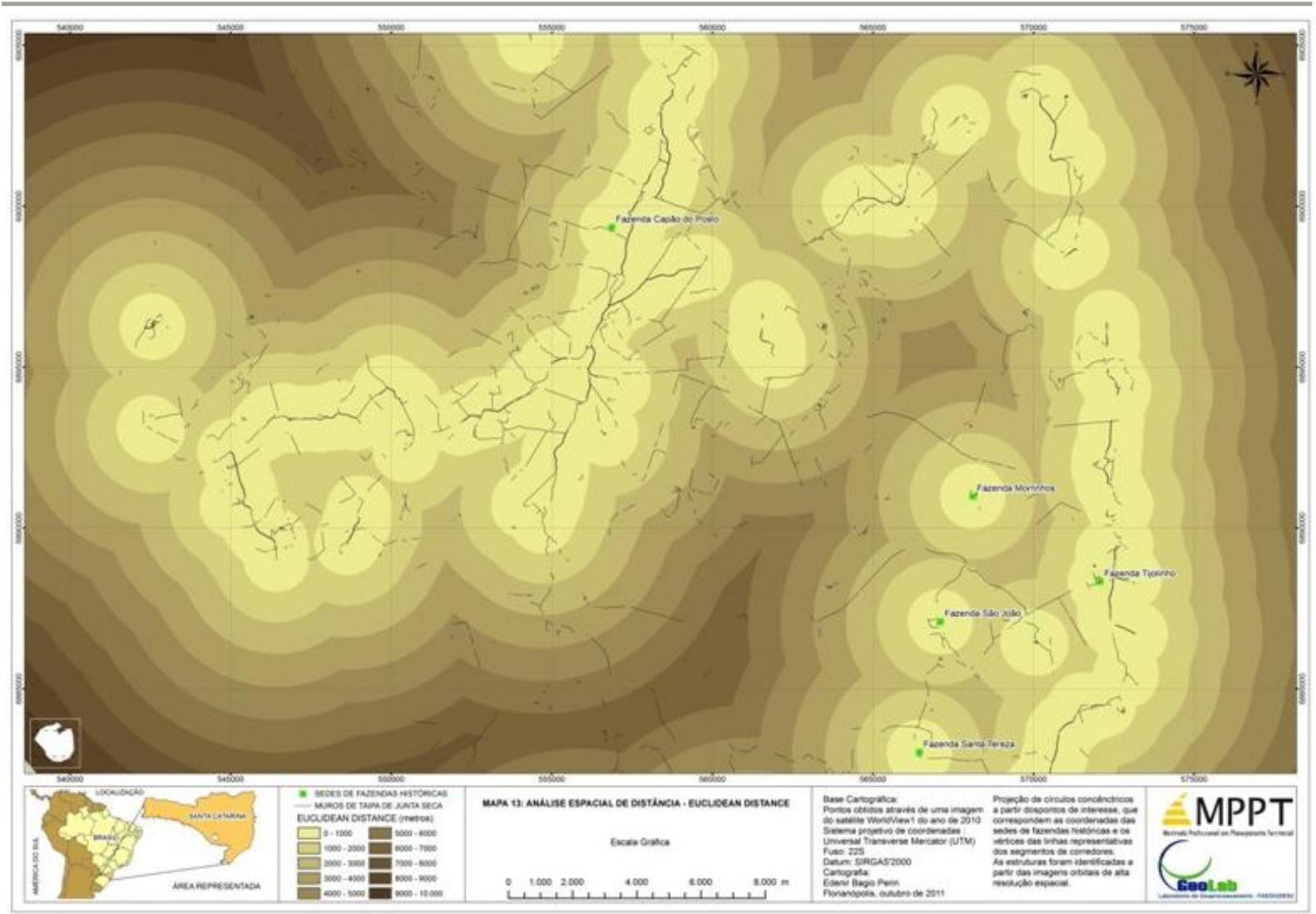

Mapa 3 - Análise espacial de distância - euclidean distance

\begin{tabular}{|c|c|} 
Quadro 3 - Valores Reclassify Euclidean Distance \\
\begin{tabular}{|c|c|}
\hline INTERVALOS DE DISTÂNCIA DA ANÁLISE \\
$(\mathbf{m})$
\end{tabular} & $\begin{array}{c}\text { VALOR DA RECLASSIFICAÇÃO DO } \\
\text { MODELO RASTER }\end{array}$ \\
\hline $0-1000$ & 10 \\
\hline $1000-2000$ & 09 \\
\hline $2000-3000$ & 08 \\
\hline $3000-4000$ & 07 \\
\hline $4000-5000$ & 06 \\
\hline $5000-6000$ & 05 \\
\hline $6000-7000$ & 04 \\
\hline $7000-8000$ & 03 \\
\hline $8000-9000$ & 02 \\
\hline $9000-1000$ & 01 \\
\hline
\end{tabular}

Fonte: Análise gerada através do software ArcGis10

\section{RESULTADOS DA Álgebra de MAPAS}

Após a realização das análises espaciais foi realizado o procedimento relacionado ao cruzamento dos dados obtidos. A álgebra de mapas pode ser entendida como um procedimento que permite a realização de operações de cruzamento de informações espaciais através de equações matemáticas tradicionais, utilizando para isso, mapas de modelos raster com atributos vinculados em cada pixel e referenciados a um sistema projetivo de coordenadas. A realização de cruzamento de dados com esta lógica está bastante difundida dentro da cartografia e das 
operações de geoprocessamento, consistindo uma das ferramentas mais importantes no campo da análise espacial.

A ferramenta do software ArcGis10 que permite a realização de álgebra de mapas chama-se raster calculator. Ela possibilita realizar uma série de operações matemáticas, como adição, subtração, multiplicação, divisão entre outros procedimentos, com dois ou mais modelos, desde que sejam seguidas algumas regras básicas relacionadas ao funcionamento do programa. As análises aqui geradas seguiram a lógica disponibilizada pelas orientações do fabricante do software que pode ser acessado via Arc Tool Box.

Com a soma de um modelo pelo outro, os pixels com valor 0 correspondentes as áreas de "sombra" sem visibilidade ganharam novos valores na adição com os pixels da análise de distância, o que a princípio causou certa confusão visual no modelo de saída. O problema foi resolvido com um novo exercício de álgebra no raster calculator.

O resultado foi multiplicado por um novo modelo de visibilidade reclassificado com apenas dois atributos. As áreas não visíveis continuaram com valor 0 e todas as áreas de visibilidade receberam valor 01 . Com este procedimento as áreas sem visibilidade voltaram ter valor 0 e as outras classes não se alteraram.

O modelo final da análise (Mapa 4) teve os valores distribuídos em classes, referentes aos níveis de sensibilidade da paisagem buscando uma classificação qualitativa. A classe correspondente as áreas não visíveis foi definida como área de sensibilidade nula, onde alterações físicas não são avistadas a partir das estruturas arqueológicas. As áreas visíveis foram divididas em quatro níveis, baixa, média, alta e muito alta.

Após a identificação dos níveis de sensibilidade visual da paisagem, novamente foram exploradas as imagens orbitais com o intuito de identificar as áreas ocupadas pela vegetação exótica recentemente introduzida na região. A soma de todos os polígonos de vegetação exótica cartografados é de 78,76 km², que corresponde a aproximadamente 9,69 \% da área de estudo.

Com a sobreposição dos polígonos de reflorestamento com o modelo final de sensibilidade visual da paisagem, foi possível identificar que já existem grandes áreas ocupadas por vegetação exótica, com incidência sobre as áreas de maior sensibilidade visual da paisagem a partir das estruturas arqueológicas. 


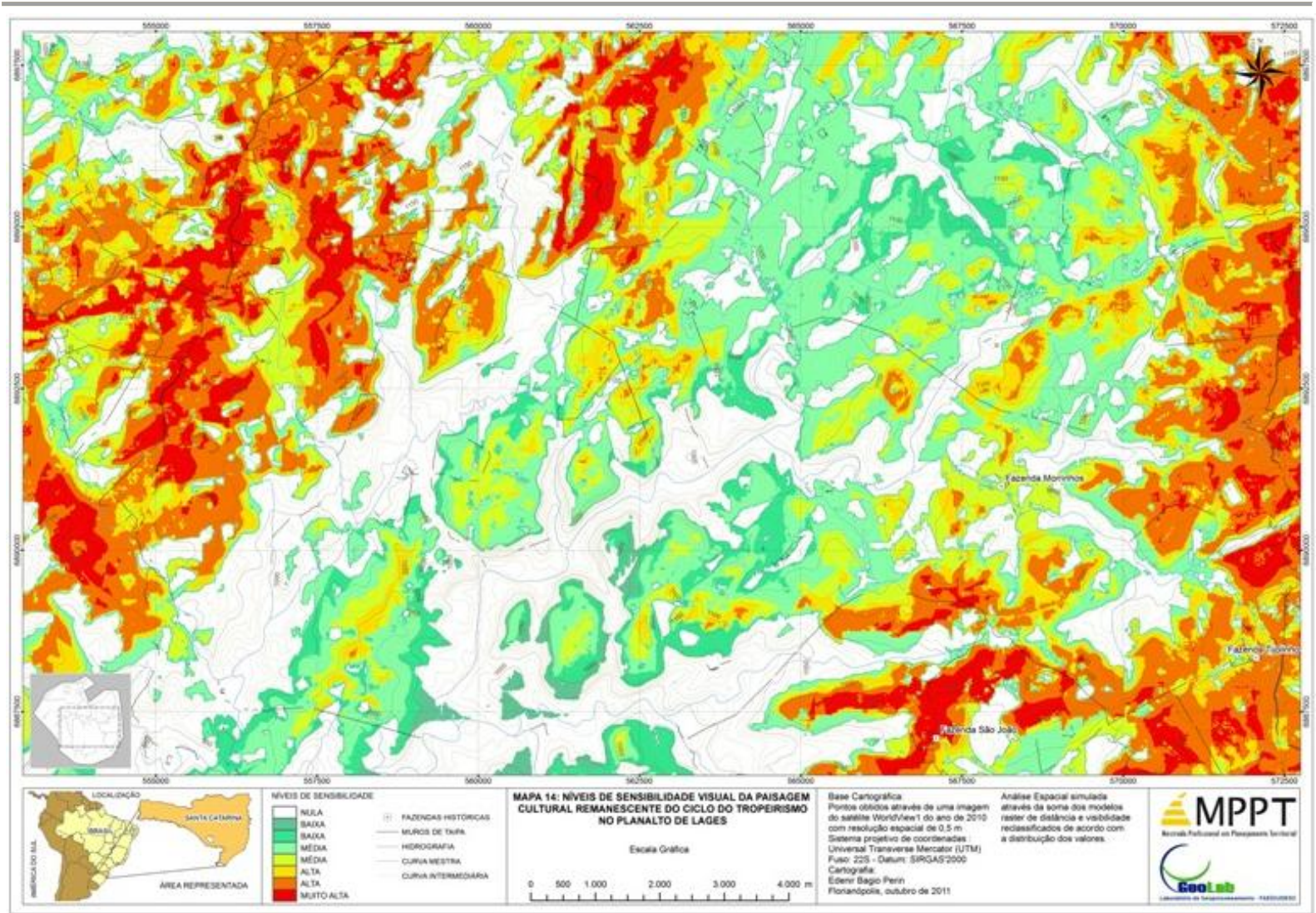

Mapa 4 - Níveis de sensibilidade visual da paisagem cultural do ciclo do tropeirismo no Planalto de Lages/SC.

As imagens orbitais de alta resolução do sensor worldview-1 permitiram boa visualização e identificação dos muros de taipa, exceto aqueles encobertos com a vegetação. Os problemas decorrentes da associação de alguns segmentos de cercas a fio de aço com muros de taipa foram resolvidos com a conferência de campo dos pontos dúbios. De modo que o mapeamento dos corredores através das imagens foi realizado com êxito. As imagens worldview-1 podem ser utilizadas para o mapeamento dos muros de taipa, desde que o mapeamento em laboratório seja acompanhado de posterior conferência em campo dos segmentos cartografados.

A soma dos modelos de visibilidade e distância possibilitou obter os níveis de sensibilidade visual da paisagem associada às estruturas arqueológicas remanescentes do Ciclo das Tropas. Este modelo pode servir de base para orientar a gestão da paisagem cultural estudada. Os diferentes níveis de sensibilidade propostos podem servir como parâmetro para que o IPHAN e a sociedade interessada estabeleçam de forma compartilhada, seguindo a lógica do instrumento jurídico que chancela a paisagem cultural brasileira, distintos usos para cada classe. Pode-se pensar em um zoneamento do espaço, de modo a compatibilizar as novas atividades econômicas cuja inserção no espaço pesquisado tende a ocorrer sem regramento.

A preservação dos remanescentes do Ciclo das Tropas no Planalto de Lages pode seguir a mesma lógica empregada pelo projeto Roteiros Nacionais de Imigração em Santa Catarina. As estruturas físicas dos corredores e sedes de fazendas podem ser protegidas de forma mais tradicional por meio da sua inscrição em um dos livros do tombo e a paisagem contígua, pode receber a Chancela de Paisagem Cultural Brasileira. Desde que, seja documentada e controlada por um 
instrumento de zoneamento do espaço, que esteja baseado nos níveis de sensibilidade da paisagem, de acordo com a lógica entre visibilidade e distância, apresentada no mapa 4.

Esses níveis podem ser definidos também como a poligonal de tombamento e proteção dos bens. Como os polígonos estão georreferenciados, o modelo cartográfico pode ser a base para a gestão da região. 0 instrumento pode ainda ser aperfeiçoado, incluindo observadores posicionados ao longo das estradas regionais o que ampliaria as áreas de proteção. Os níveis de sensibilidade e interesse propostos também podem ser objeto de estudos de campo, visando estabelecer quais as atividades econômicas são mais adequadas para cada classe e também, que intervenções são adequadas a cada área.

\section{REFERÊNCIAS BIBLIOGRÁFICAS}

AB' SABER, Aziz. N. Os Domínios de Natureza no Brasil: potencialidades paisagísticas. São Paulo: Ateliê Editorial, 2003.

CREMON, Édipo Henrique; FILHO, Edward Elias de Souza. Geração de MDEs para o Alto Rio Paraná através de dados ASTER e SRTM. Anais do XVIII EIAC, Londrina, 2009.

ESRI - Viewshed (Spatial Analyst) Using iewshed and Observer Points for visibility analysis (2011).

FUCKNER, Marcus André. Aplicação de imagens ASTER no estudo do ambiente urbano de São Paulo e Rio de Janeiro. INPE, 2008.

KNEIP, Andréas. O Povo da Lagoa: uso do SIG para modelamento e simulação na área arqueológica do Camacho. Tese de Doutorado, Universidade de São Paulo. São Paulo, 2004.
MOURA, Anara Mourão. Geoprocessamento na gestão e planejamento urbano. Belo Horizonte. Ed. da autora, 2003.

PARMA, Gabriel Cremona. Processamento de imagem ASTER para obtenção e imagem ortorretificada do município de Palhoça, SC, Brasil. Florianópolis: INPE - Anais do XIII Simpósio Brasileiro de Sensoriamento Remoto, p. 6019-6026, 2007.

PERIN, Edenir Bagio; BOSCATTO, Flavio; FARIAS, Deisi Scunderlick Eloy. O Sistema de Informações Geográficas (SIG) Aplicado à Análise Espacial de Sítios Arqueológicos. Estudo de caso no alto curso da bacia hidrográfica do Rio Tubarão. Artigo. Curso de Processamento das Informações Geográficas na Gestão Ambiental. Tubarão, 2008.

SANTOS, Milton. Por uma Geografia nova. 2 Ed. São Paulo: Hucitec. 1980. 


\title{
NOTAS
}

\begin{abstract}
${ }^{i}$ Entre os anos de 2007 e 2011 o IPHAN oficializou o tombamento de 61 edificações identificadas pelo projeto Roteiros Nacionais de Imigração em Santa Catarina. O conjunto paisagístico atrelado aos bens tombados foi o primeiro a receber a Chancela de Paisagem Cultural Brasileira.
\end{abstract}

${ }^{\text {ii }}$ Nível Relativo do Mar.

iii Before Present. O presente para a Arqueologia é tido por convenção como o ano de 1950. Nesta década foi descoberto o método de datação radiocarbônica.

iv A análise não funciona para features corrrespondentes a polígonos, somente para arquivos de pontos e linhas.

v A ferramenta Reclassify do software ArcGis10 possibilita reclassificar as classes de um modelo raster de acordo com a necessidade do usuário. É possível modificar os valores das classes do modelo que modificará os dados na tabela de atributos da feição. 